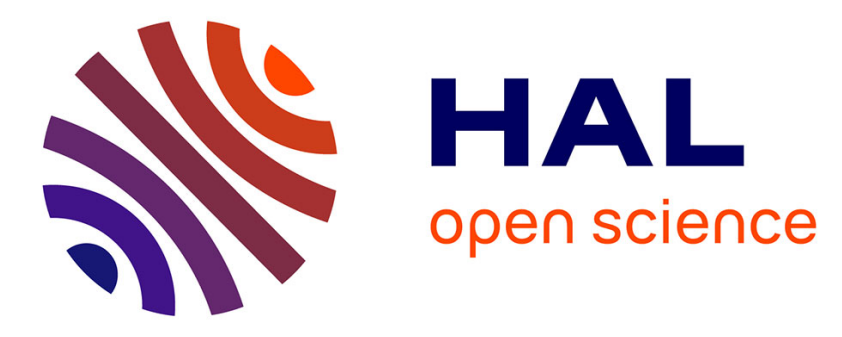

\title{
Water transport in parchment and endosperm of coffee bean
}

Alejandra Ramirez-Martinez, M.A. Salgado-Cervantes, G.C.

Rodriguez-Jimenes, M.A. Garcia-Alvarado, Fabien Cherblanc, Jean-Claude

Benet

\section{To cite this version:}

Alejandra Ramirez-Martinez, M.A. Salgado-Cervantes, G.C. Rodriguez-Jimenes, M.A. GarciaAlvarado, Fabien Cherblanc, et al.. Water transport in parchment and endosperm of coffee bean. Journal of Food Engineering, 2013, 114, pp.375-383. 10.1016/j.jfoodeng.2012.08.028 . hal-00754699

\section{HAL Id: hal-00754699 \\ https://hal.science/hal-00754699}

Submitted on 20 Nov 2012

HAL is a multi-disciplinary open access archive for the deposit and dissemination of scientific research documents, whether they are published or not. The documents may come from teaching and research institutions in France or abroad, or from public or private research centers.
L'archive ouverte pluridisciplinaire HAL, est destinée au dépôt et à la diffusion de documents scientifiques de niveau recherche, publiés ou non, émanant des établissements d'enseignement et de recherche français ou étrangers, des laboratoires publics ou privés. 


\title{
Water transport in parchment and endosperm of coffee bean
}

\author{
3 Ramírez-Martínez A. ${ }^{1,2}$, Salgado-Cervantes, M.A. ${ }^{2}$, Rodríguez-Jimenes G.C. ${ }^{2}$, \\ García-Alvarado M.A. ${ }^{2}$, Cherblanc F. ${ }^{1}$, Bénet J.C. ${ }^{1}$ \\ ${ }^{1}$ Laboratoire de Mécanique et Génie Civil, Université Montpellier 2, CNRS, \\ Place Eugène-Bataillon 34095, Montpellier cedex 5, France \\ (1)

$$
\text { Tel.:(+33) 467-149-643 }
$$ \\ ${ }^{2}$ Chemical and Biochemical Engineering Department, Instituto Tecnológico de Veracruz \\ Av. Miguel A. de Quevedo 2779, 91860 Veracruz, Ver. México \\ Tel.:(+52) 2299345701
}

E-mail: jean-claude.benet@univ-montp2.fr

\begin{abstract}
This paper aims at contributing to identify the eventual regions where fungus Aspergillus ochraceus could grow and produce ochratoxin A (OTA) during drying of coffee beans. Internal structure of coffee bean was analyzed by optical microscopy for endosperm and parchment. From the expression of the dissipation in the grain due to the water transport, we show that a relationship formally analogous to an equation of diffusion governs the water transport. Three structures with mass transfer resistance potential are studied: parchment, silver skin and endosperm. An experimental technique to study the water transfer into the parchment was proposed. In the endosperm, for moisture contents above $65 \%$, a constant transport coefficient controls the drying kinetics of the whole bean. Below this moisture content, water transport coefficient (with and without silver skin) were significantly lesser than those for the whole bean. This is firstly due to the reduction of the pore space occupied by water and second to the increasing bonding energy between solid structure and water as moisture content decreases. The contribution of parchment to the protection of the endosperm is highlighted.
\end{abstract}

Keywords: Coffee internal structure, drying, sorption isotherms, water transport coefficient, ochratoxin A.

\section{NOMENCLATURE}



$41 \quad k_{c}$
$42 \quad K_{e q}$
$43 \times \mathrm{X}_{-}^{-}$
$44 \quad l$
$45 \quad m$
$46 \quad M$
$47 \quad N$
$48 \quad r$
$49 \quad R$
$50 \quad S$
$51 t$
$52 T$
$53 \quad U$
$54 v$
$55 \quad V$
$56 \quad x$
57
58
Greek symbols
59
$60 \mu$
$61 \rho$
$62 \Delta_{w}$
63

\section{Subscripts}
65
660
$67 \quad 1$
$68 \quad a$
$69 a v$
Mass transfer coefficient
$\mathrm{m} \cdot \mathrm{s}^{-1}$
Average water distribution constant between phases
Water transport coefficient in a structure
$\mathrm{kg} \cdot \mathrm{s} \cdot \mathrm{m}^{-3}$
Characteristic length for diffusion
$\mathrm{m}$
Mass
Molecular mass
Mass flux
Mass transfer resistance
Gas constant (8314.0)
Entropy
time
Temperature
Internal energy
apparent velocity
Volume
Moisture content
$\mathrm{kg}$
$\mathrm{kg} \cdot \mathrm{kgmol}^{-1}$
$\mathrm{kg} \cdot \mathrm{m}^{-2} \cdot \mathrm{s}^{-1}$
$\mathrm{kg} \cdot \mathrm{m}^{-2} \cdot \mathrm{s}^{-1}$
$\mathrm{J} \cdot \mathrm{kgmol}{ }^{-1} \cdot \mathrm{K}^{-1}$
$\mathrm{J} \cdot \mathrm{K}^{-1}$
S
$\mathrm{K}$ or ${ }^{\mathrm{O}} \mathrm{C}$
$\mathrm{J}$
$\mathrm{m} \cdot \mathrm{s}^{-1}$
$\mathrm{m}^{3}$
$\mathrm{kg} \cdot \mathrm{kg} \mathrm{dm}$
Chemical potential
Density
Water transport coefficient
$\mathrm{J}^{\cdot} \mathrm{kg}^{-1}$
$\mathrm{kg} \cdot \mathrm{m}^{-3}$
$\mathrm{m}^{2} \cdot \mathrm{s}^{-1}$
At initial or in one side
At the other side
For air
Averaged 


$\begin{array}{lll}70 & e & \text { At equilibrium } \\ 71 & e n & \text { In endosperm } \\ 72 & p a & \text { In parchment } \\ 73 & s & \text { For dry matter } \\ 74 & w & \text { For water } \\ 75 & \alpha & \text { In a heterogeneous structure }\end{array}$

\section{INTRODUCTION}

Coffee is the second most valuable legal commodity in the world (Pendergrast, 1999;

80 Kouadio et al., 2007). According to FAO (2008), coffee is sold in 78 countries around the world and

8120 to 25 million families depend on its trade. Coffee cherries are subjected to two different post-

82 harvest treatments where the main objectives are to remove the various layers surrounding coffee

83 beans and to dry them in order to prevent the growth of microorganisms (Paulino De Moraes \&

84 Luchese, 2003; Suárez-Quiroz et al., 2004). The most usual treatment is called "wet". In this

85 method, coffee cherries are put in a tank filled with water in order to separate the defective beans

86 and to remove the pulp and mucilage. Then, "washed" coffee beans are dried. An alternative is to

87 use the "dry" method in which coffee cherries are directly dried to get grayish beans known as

88 "coffee coke" or "natural coffee". After drying, the parchment and the other layers covering the 89 beans are removed mechanically to get the "green" coffee.

90 Regardless the post-harvest method, drying can be carried out naturally (using sun) and/or

91 artificially (using dryers). Drying has been identified as a step where fungal contamination can

92 develop (Frank, 2000; Paulino de Moraes \& Luchese, 2003; Taniwaki et al., 2003; Kouadio et al.,

93 2007). Particularly, Aspergillus ochraceus, a common host fungus, produces a toxin (Ochratoxin A,

94 OTA) which have teratogenic, immunotoxic and possibly neurotoxic and carcinogenic properties.

95 Moreover, this toxin has a high thermal stability up to $250^{\circ} \mathrm{C}$ (FAO, 2008). Considering the risk for

96 human health, fungus development should be avoided to prevent OTA production. Among the

97 factors that govern the fungal development, water activity $\left(a_{w}\right)$ has been underlined to be the most

98 important (Suárez-Quiroz et al., 2004; Kouadio et al., 2007). Actually, temperature influences the

99 production rate while not being a limiting factor (Suárez-Quiroz et al., 2004). The optimal conditions

100 for the growing of $\mathrm{A}$. ochraceus are given by a water activity of 0.95 and a temperature of $35^{\circ} \mathrm{C}$

101 while its development is inhibited with a water activity lower than 0.80 and a temperature less than

$10210^{\circ} \mathrm{C}$ (Suárez-Quiroz et al., 2004). From this research, it results that 0.8 is a critical value for the

103 prevention of OTA production. However, it represents an average value over the whole coffee bean

104 that does not account for the water distribution resulting from moisture diffusion during the drying

105 process. Moreover, $A$. ochraceus develops at the coffee bean surface while fungal spores penetrate 
about a few micrometers inside. Then, the development of Aspergillus ochraceus in coffee bean

107 may be seen as a competition between its capacity of water supply and a decrease on the water

108 activity in the internal parts of the grain consecutive to drying. When coffee bean has not been

109 damaged (cracks, separation of the parchment) this competition takes place on the surface of the

110 grain, and it is the combination between the water activity and the water transport properties in the

111 parchment and the surface layer of the endosperm. As consequence, it seems essential to analyze

112 precisely the water distribution rather than its average content (Frank, 2000).

113 During the drying process, water transport coefficient is one of the most important 114 parameters because it governs water distribution in the grain (Geankoplis, 1998). Usually, water 115 transport is evaluated from the fitting of an adequate Fick's law equation to experimental drying 116 kinetic (Mulet, 1994; Maroulis et al., 1995; Wang \& Brennan, 1995; Bialobrzewski \& Markowski, 117 2004; Efremov \& Kudra, 2004; Hernández et al., 2008). Sfredo et al. (2005) and Correa et al. 118 (2006) have determined the water transport coefficient in coffee cherries. Both rely on a Crank's 119 solution of Fick's law valid for sphere (Crank, 1975) since it is a fair approximation of the coffee 120 cherry geometry. The water diffusivity values measured obtained by Sfredo et al. (2005) lie in the 121 range $\left[0.1-1 \times 10^{-10}\right] \mathrm{m}^{2} \cdot \mathrm{s}^{-1}$ at $45^{\circ} \mathrm{C}$ and $\left[0.3-3 \times 10^{-10}\right] \mathrm{m}^{2} \cdot \mathrm{s}^{-1}$ at $60^{\circ} \mathrm{C}$, while those found by 122 Correa are $2.91 \times 10^{-10} ; 3.57 \times 10^{-10}$ and $4.96 \times 10^{-10} \mathrm{~m}^{2} \cdot \mathrm{s}^{-1}$ at 40,50 and $60^{\circ} \mathrm{C}$ respectively. To 123 improve the geometrical description of coffee cherries, Hernández et al. (2008) developed a Fick's 124 law solution considering a non-conventional geometry: prolate spheroid geometry.

125 In many products with a complex micro-structure such as wood and pasta (Mrani \& Bénet, 126 2005), Agar gel (Mrani et al., 1995) and latex (Auria et al., 1991), water transfer is controlled by 127 physicochemical and mechanical interactions occurring at the interfaces between phases: 128 capillarity, osmotic effects, surface adsorption, liquid-gas phase change (Bénet et al., 2009), water 129 transfer between cells and walls. Therefore, transfer coefficients represent a superposition of 130 different phenomena and depend on moisture content. In particular water transfer coefficients 131 cancel as the moisture content tends towards zero. In this case, the use of diffusion and of Crank's 132 solutions to describe mass transfer may be questionable for media presenting a complex 133 microstructure.

134 Finally, the objective of this study is to contribute, through microscopic analysis and local 135 mass transfer measurements, the potential regions where fungus could develop and produce OTA 136 during drying processes. Therefore, this paper deals with the four following aspects: 1) Analysis by 137 a thermodynamic approach of the law for water transport in a complex media 2) Microscopic 138 observation of coffee bean in order to identify the different structures of coffee beans and their 139 heterogeneity; 3) Characterization of the relationship between water activity and moisture content 140 and 4) Study of the dependence of transport properties on moisture content. 
These physical characteristics will be useful to improve the numerical modeling of the 142 drying process. By simulating various drying scenarios, it should lead to propose different strategies 143 to avoid the development of fungus.

\section{Thermodynamic approach to water transport in complex media}

Complex media such as food, gel and biological tissues are characterized as having several structures ( $\alpha$ at Equation 1) which can be solid, liquid or gas phases, superficial layers, film layers, membranes, cells, and cell walls. In such complex media the use a priori of a law similar to Fick's law seems not appropriate. However many experimental results of media as complex as coffee endosperm (wood, gels, food) seem to show that this law is sufficient to describe water transfer at the macroscopic level as it will be demonstrated in the following discussion. potential, given by (Callen, 1985):

159 Where $\mu_{w^{\alpha}}$ is the water chemical potential at structure $\alpha$ and is defined as the partial derivative

160 of the internal energy contained in a Representative Elementary Volume (REV), with respect to 161 water mass, taking entropy, volume of $\alpha$ in the REV and the mass of the other constituents as

162 constants. The chemical potential characterizes the action of the other media constituents upon the 163 water from the structure ${ }^{\alpha}$, regardless of the form of the water: liquid, gas, adsorbed by the liquid 164 phases, in films or in superficial layers.

165 Water transport phenomena in the structure obey the second principle of thermodynamics.

166 Assuming uniform and constant temperature, in the absence of chemical reactions and neglecting 167 the effect of gravity, the dissipation in structure $\alpha$ due to water transport phenomena in all forms 168 can be written as (Müller, 2001; Kuiken, 1994):

$$
D_{w} \alpha=-\rho_{w} \alpha v_{w} \alpha \mu_{w} \alpha \geq 0, \quad \forall \alpha
$$

172 Where $D_{w^{\alpha}}$ is the dissipation in structure ${ }^{\alpha}$. Considering the Gibbs Duhem relationship (Callen, 173 1985) applied to each phase, Eq. 2 is retained when water transport is handled by the mechanisms 174 of filtration of the phases and their surface layers (Prigogine \& Mazur, 1951; Bénet \& Jouanna 
1982). The positivity of the dissipation term is ensured if the mass flow of water in structure $\alpha$ is of

176 the following form:

$$
\rho_{\alpha_{w} v_{w} \alpha}=-K_{\alpha} \quad X \alpha \quad \nabla \mu_{w} \alpha, \quad \forall \alpha
$$

Where $X_{\alpha}$ is the moisture content of the structure $\alpha$. Eq. 3 is the expression of the 182 (Callen, 1985) i.e. regardless the form in which a constituent is present (water in this case), it moves 183 from high chemical potential values to low chemical potential values. The function $K_{\alpha} \quad X_{\alpha}$ is

184 positive and represents the water transport coefficient within $\alpha$. This function depends on the 185 moisture content of $\alpha$. In agricultural products such as coffee, cocoa and wheat the characteristic 186 dimensions of the structures $\alpha$ are very small if compared with those of the grain. For coffee, as 187 will be shown later, the relationship between cell size and the grain is on the order of $10^{-3}$; the ratio 188 for the cell wall is about $10^{-4}$. We will assume that the equilibration time between two grain 189 structures $\alpha$, for example, between the cell and the cell wall is very fast compared to the drying 190 time which can be of the order of one day. We adopt the assumption of local equilibrium at $\alpha:$ the 191 thermodynamic equilibrium of water between the different structures is performed. This hypothesis 192 implies that the chemical potential of water is the same in all structures $\alpha$ and its chemical 193 potential is symbolized by $\mu_{w}=\mu_{w^{\alpha}} \forall \alpha$.

Then, the global flux of water is obtained by, variation of moisture content $X_{\alpha}$ as a function of water activity $\left(a_{w} \alpha\right)$ in the structure $\alpha$. We will

201 use the inverse function $a_{w^{\alpha}}=a_{w^{\alpha}} \quad X_{\alpha}$. The chemical potential of water mass in the structure 202 is given by the relationship (Callen, 1985):

203

$$
\rho_{w_{w} v_{w}}=\sum_{\alpha} \rho_{\alpha_{w}{ } \alpha_{w}}=-\left(\sum_{\alpha} K_{\alpha} \quad X \alpha_{\alpha}\right) \nabla \mu_{w}
$$

Each structure is characterized by a desorption isotherm, which represents the monotonic

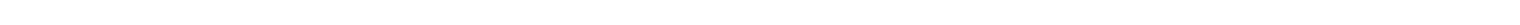

205

$$
\mu_{w^{\alpha}}=\mu_{w}=\frac{R T}{M_{w}} \ln a_{w} \alpha \quad X \alpha \quad, \forall \alpha
$$


206 As $\mu_{w}$ value has being fixed, the moisture contents of each structure $X_{\alpha}$ adapt to meet the 207 equality of chemical potentials (Eq. 5). The average moisture content of the medium in a REV is 208 defined by,

$$
X=\frac{m_{w}}{m_{s}}=\sum_{\alpha} \frac{X \alpha m_{s} \alpha}{m_{s}}
$$

212 Where $m_{w}$ is the total mass of water in the REV, $m_{s}=\sum_{\alpha} m_{s} \alpha$ is the total mass of solid in the

213 REV and $m_{s} \alpha$ is the mass of solid in the structure $\alpha$ in the REV. In the absence of dissolution or

214 chemical reactions, the relationships $m_{s} \alpha / m_{s}$ are constant, knowledge of moisture content in the

215 different structures $x_{\alpha}$ give the value of $X$ by (Eq.6) and $\mu_{w}$ by (Eq.5). So there is a relationship

216 between $X$ and water activity denoted by $a_{w} \quad X \quad$ :

$$
\mu_{w}=\frac{R T}{M_{w}} \ln a_{w} \quad X
$$
value, Eq. 6 gives the moisture contents in each structure. There is a relationship of the form $222 X_{\alpha}=X_{\alpha} \quad X \quad, \forall \alpha$ and therefore the coefficients $K_{\alpha} \quad X_{\alpha} \quad$ in Eq. (4) can be expressed as a 223 function of $X$. The global transport coefficient can also be expressed as:

$$
K \quad X=\sum_{\alpha} K_{\alpha} \quad X_{\alpha} \quad X
$$

Given this relationship, the overall (global) flux of water is expressed by:

$$
\rho_{w} v_{w}=-K \quad X \quad \nabla \mu_{w}
$$

From Eq. (7), Eq. (9) can be written as:

$$
\rho_{w} v_{w}=-{ }_{K} X \frac{\partial}{M_{w} a_{w}} \frac{\partial a_{s} \nabla}{\partial \varepsilon_{s} X-} \varepsilon_{s} X-
$$


Defining,

$$
{ }_{{ }_{w}} \boldsymbol{X}={ }_{K} \boldsymbol{X} \underset{M_{w} a_{w}}{-R T} \frac{\partial a_{s}}{\partial \varepsilon_{s} X-}
$$

Eq. (10) becomes,

$$
\rho_{w} v_{w}=-\Delta_{w} \mathbb{X} \bar{\nabla} \varepsilon_{s} X-
$$

Formally Eq. (12) is presented in a similar form to Fick's law. This is valid only to describe the diffusion of a constituent in a unique phase: solid, liquid or gas. The transport coefficient depends on moisture content. With the assumption of local equilibrium, Eq. (12) allows us to describe the water transport in a complex media, formed of juxtaposed structures, in which various mass transport mechanisms are present. This relationship involves the assumption of a thermodynamic equilibrium localized between the different forms of water. The formal similarity between Eq. (12) and Fick's law authorizes the use of all the mathematical developments concerning this law. In particular the use of mathematical solutions developed by Crank for particular geometries remains applicable. However, it is improper to call $\Delta_{w} X$ as water diffusivity in media because it combines several transport phenomena; it will be called the water

\section{MATERIALS AND METHODS}

Fermented washed coffee beans (Arabica variety) from crops 2008 and 2009 were used in this study. Both samples were obtained from "Beneficio La Cuchilla" located in Huatusco, Veracruz, Mexico. Moisture content was determined by the method from AOAC (1990) No. 22.013, in which

262 samples are introduced into a vacuum oven and subjected to an absolute pressure of $13.3 \mathrm{kPa}$ and 263 a temperature of $60^{\circ} \mathrm{C}$ until two consecutive weights differ from less than $10^{-4} \mathrm{~g}$.

\subsection{Coffee bean general structure characterization}

For the characterization of the general structure, measures of the three principal axes of fermented washed coffee beans were made using an electronic Vernier. Also a computer representation was generated from a real coffee bean. Three cameras where set up surrounding 
one coffee bean and shoot at the same time. The obtained pictures served to generate a geometrical model using the software ImageWorks @ (2008).

\subsection{Preparation of samples for microscopic observation of coffee bean}

The cellular distribution of coffee bean was studied from coffee bean slices. The resulting slices were stained by immersion in safranin for $30 \mathrm{~min}$, followed by washings with ethanol of different concentrations, and left in contact with fast green for $10 \mathrm{~min}$, finally they were washed in pure ethanol and observed in an optical microscope Leica DM 500. Pictures of the slices were taken using a camera coupled to the microscope. Also the cell diameter and cellular wall thickness was measured using the software Image J (C) (2008). To analyze the internal heterogeneity and transport properties, subsamples of coffee beans were prepared. Using a special cylindrical cutting tool (Fig.1.a), coffee beans were separated in 6 different parts (Fig. 1.b). In the following discussion these parts are denominated: parchment (a), silver skin (b), endosperm part 1 (c), endosperm part 2 (d), extremities $(e, f)$. The 2 parts of the endosperm (c, d) are separated by the natural discontinuity observed in Fig. 1.

\subsection{Distribution of water activity}

In order to check if water content heterogeneities can be observed throughout a coffee bean, sorption isotherms of the different parts were determined. With the subsamples prepared (Fig. 1.b), 5 different sorption isotherms have been determined by considering the whole coffee bean and the 4 internal parts: parchment (a), endosperm part 1 (c), endosperm part 2 (d) and extremities (e, f). The silver skin (b) is too thin and light to get some accurate sorption measurements.

Sorption isotherm points for water activities less than 0.92 were obtained by the standard method using saturated salt solutions at $35^{\circ} \mathrm{C}$ (AOAC, 1990), while water activities between 0.92 and 0.99 were measured by means of a mechanical method (Ouoba et al., 2010). This new method allows to measure high water activity values in a shorter time (about one day) avoiding the risk of fungal development.

\subsection{Mass transfer in coffee bean}

To identify eventual heterogeneities in water transport, water transport coefficients were evaluated with 4 different samples: the whole bean, the endosperm with silver skin, the endosperm without silver skin and the parchment.

\subsubsection{Determination of the water transport coefficient in the endosperm}

Analytical solutions of the Fick's equation were established for various configurations

306 (Crank, 1975). In the case of an infinite slab, the asymptotic solution is given by, 


$$
\frac{X-X_{e}}{X_{0}-X_{e}}=\frac{8}{\pi^{2}} \exp \left(-\frac{\pi^{2} \Delta_{w e n} t}{4 l^{2}}\right)
$$

310 This asymptotic solution is valid only for $x_{-}-x_{e} / x_{0}-x_{e}<0.7$ (Crank, 1975). To develop this 311 solution, we made the following hypothesis (i) initial moisture content is uniform, (ii) interfacial mass 312 transfer negligible and (iii) a constant transport coefficient over time which implies to consider short 313 times. To approach these conditions, we adopted an incremental method which consists in two 314 stages: (i) equilibrium of a coffee sample with a saturated salt solution to obtain uniform initial 315 moisture content; (ii) change in the saturated salt solution to start the drying process. Ten samples 316 of endosperm, previously separated from coffee beans with and without silver skin, were glued on 317 an aluminum plate. The aluminum plate was disposed in the device described in Fig. 2 in which the 318 samples were equilibrated at $35^{\circ} \mathrm{C}$ with a saturated salt solution. The equilibrium of the samples 319 was checked by the weight stability over time. The initial salt solution was then replaced by a potassium acetate solution fixing water activity at 0.21 . From that point, the plate weight was recorded continuously. At the end of the experiment, the moisture content was determined by 322 standard methods (AOAC, 1990). The water transport coefficient in endosperm $\left(\Delta_{\text {wen }}\right)$ was 323 calculated by fitting Eq. (13) to the weight loss kinetics at times that satisfy $x^{-} x_{e} / x_{0}-x_{e}$

$324<0.7$. Like in this case the sample was dehydrated by one side, the characteristic length for diffusion $(l)$ is the complete thickness of the sample. This procedure was repeated with different initial salt solutions in order to impose water activities of $0.43,0.50,0.62,0.75$ and 0.84 .

The experimental device described in above paragraph is such that the endosperm sample were dehydrated by one side under natural convection, therefore in order to verity assumption (ii), the mass Biot number defined by (Córdova et al., 1996) and described in Eq. (14) was estimated.

$$
B i_{m}=\frac{k_{c} l}{\Delta_{w e n}} \frac{K_{e q} \rho_{s a}}{C_{s e n}}
$$

Where the mass transfer coefficients $\left(k_{c}\right)$ must be calculated for natural convection. The empirical correlations reported by Geankoplis (1998) were used.

3.4.2 Determination of water transport coefficient on a whole grain with high moisture content

At coffee bean fresh state, it can be admitted that the porous space is saturated with water. Water transport may be characterized by an averaged water transport coefficient $\left({ }^{\Delta}{ }_{\text {wav }}\right)$ which 
corresponds at the moisture content of green coffee bean supposed uniform on all the grain. In order to take account of the shape of the grain, Hernandez et al., (2008) show that prolate spheroid

342 geometry fairly approximates the shape of a coffee bean, and the asymptotic solution Fick's second 343 law in this case is,

$$
\frac{X-X_{e}}{X_{0}-X_{e}}=0.78 \exp \left(-\frac{12.3^{\Delta}{ }_{w a v} t}{l^{2}}\right)
$$

In this case, the characteristic length for diffusion $(l)$ is the focal distance of prolate spheroid. In 348 order to measure the averaged water transport coefficient in the whole coffee bean, tests were conducted in a pilot plant composed of a fixed bed dryer and an imposed transversal air flow with a $0.0024 \mathrm{~m}^{2}$ section. The air flow can be regulated up to $2 \mathrm{~m} \mathrm{~s}^{-1}$ and $80^{\circ} \mathrm{C}$. Tests were carried at two temperatures: $35^{\circ} \mathrm{C}$ and $45^{\circ} \mathrm{C}$ and the air velocity was imposed at $1.5 \mathrm{~m} \mathrm{~s}^{-1}$. These conditions are similar to those encountered in solar drying where the risk of OTA development is high (Mburu, 1999). In each test, the drying kinetics is evaluated by recording the weight loss as function of time and moisture content is calculated at the end. Averaged water transport coefficient was calculated by fitting Eq. (15) to the experimental results that satisfied $x^{-}-x_{e} / x_{0}-x_{e}<0.7$ with semi-log regression. Statistical validation was performed through the $95 \%$ confidence interval of the parameter fitted.

\subsubsection{Determination of the transfer coefficient in the parchment}

Parchment samples look like $6 \mathrm{~mm}$ diameter and $0.1 \mathrm{~mm}$ thickness confetti (a in Fig. 1). The thickness of parchment is negligible with respect to endosperm and the methodology described in previous section is not appropriate. Moreover, since the thickness is not uniform, discrepancies are introduced in the estimation of diffusivity. Therefore, we adopt an averaging point of view by relying on a global water transfer resistance. The water flux $\left(N_{w}\right)$ is assumed to be proportional to the water activity difference $\boldsymbol{\delta}_{w 1}-a_{w 0}$-imposed on both sides of the parchment,

Thus, an experimental method has been developed to determine the water transfer resistance $(r)$ 370 of the parchment. The parchment sample was disposed between two deformable polypropylene tubes (T1, T2) (Fig. 3) and compressed. Then, the compression effort was maintained by needless

372 (E) ensuring perfect airtightness. Each tube is connected to saturated salt solutions imposing 2 
373 different values of water activity, $a_{w 0}$ on bottom surface and $a_{w 1}$ on top. The entire device was

374 placed in a closed thermo-regulated chamber at $35^{\circ} \mathrm{C}$, and the weight of bottom salt solution is 375 recorded continuously. The water activity difference activates a water flux $N_{w}$ through the 376 parchment sample evaluated by the weight loss or gain of the bottom salt solution. The flux was 377 calculated from the slope obtained by linear regression in the linear zone of weigh vs. time plot. To 378 increase the water vapor flux and therefore decrease measurement discrepancies, five systems 379 (Fig. 3) were set together. Tests have been carried out with 3 and 5 devices and compared to 380 validate the method. The moisture content of the parchment is evaluated from the average of 381 moisture content imposed on both sides by water activities $a_{w 0}$ and $a_{w 1}$ using the sorption 382 isotherm determined as is described in section 3.3. Experimental conditions are summarized in 383 Table 1. Statistical validation was performed through 95\% interval confidence of the slope obtained 384 by linear regression. A comparison between endosperm and parchment water transport coefficients, 385 may be obtained from the Eq. (16) expressed in terms of parchment water transport coefficient ( $\left.386 \Delta_{w p a}\right)$ as follows,

$$
N_{w}=\frac{\Delta_{w p a} C_{s p a}}{h} \mathbb{X}_{1}-X_{0}-
$$

where $X_{0}$ and $X_{1}$ are the parchment moisture content at water activities $a_{w 0}$ and $a_{w 1}$ respectively.

\section{RESULTS AND DISCUSSION}

\subsection{Characterization of the structure}

\subsubsection{Characteristic dimensions}

Characteristic dimensions of coffee bean were determined as exposed in section 3.1. The obtained values were for the major axis: $11.6 \mathrm{~mm}$, small axis: $8.1 \mathrm{~mm}$, thickness: $4.6 \mathrm{~mm}$, surface: $1.293 \times 10^{-4} \mathrm{~m}^{2}$, volume: $1.99 \times 10^{-7} \mathrm{~m}^{3}$, and the focal distance calculated considering a prolate

401 spheroid geometry (Eq. 15) was $4 \times 10^{-3} \mathrm{~m}$.

\subsubsection{Internal structure}

Cross-sections perpendicular to the coffee major axis were sliced from fermented washed 405 coffee beans. All slices were prepared as described in section 3.2 and images were taken by optical 406 microscopy. The objective is to identify some heterogeneities in the internal structure has already 407 reported (Eira et al., 2006; De Castro \& Marraccini, 2006). 
Observations reveal a rupture of the tissue in the upper part of the endosperm (Fig. 4). Since it does not have a specific anatomical name, it will be called "natural discontinuity". Mucilage left-over was found in the natural discontinuity as shown by Sutherland et al. (2004).

Heterogeneities in physical properties can result from variations in the cell arrangement and distribution. When focusing at the cell shape, two different geometries are encountered:

413 "rectangular" and "polyhedral" depending on the number of cell edges. On cross-section images, it 414 is generally observed that the natural discontinuity is surrounded by "rectangular" cells while the 415 rest of endosperm is made up of "polyhedral" cells. Therefore, the cells pattern and distribution 416 seems to be oriented by the natural discontinuity. However, even though some differences in the 417 cells arrangement are observed, internal structure dimensions are almost uniform over the whole 418 bean. On a zooming image (Fig. 5), cells dimensions are indicated. Cell diameters were between 30 419 to $60 \mu \mathrm{m}$ while the wall thickness ranges from 9 to $11 \mu \mathrm{m}$.

420 The microstructure of parchment is shown in Fig. 6. One can notice the fibers with a high 421 level of cross-linking in agreement with the description made by Kasser \& Kasser (1969). Regarding 422 to the chemical composition, the main compound of endosperm is a polymannan while parchment is 423 principally composed of lignin and pentose. Thus, coffee parchment has a structure that strongly 424 differs from the endosperm and this aspect should result in differences in physical properties.

\subsection{Sorption isotherms}

Five sorption isotherms were obtained: parchment, internal and external endosperm, 428 extremities and whole bean. The experimental points are plotted in Fig. 7. The continuous lines 429 represent the best fit with GAB model except at high water activities $\left(a_{w}>0.84\right)$ where the Ferro430 Fontan model is used (Ferro-Fontan et al., 1982). No significant differences between the sorption 431 isotherms of the endosperm, extremities and the whole bean were observed. However, the 432 behavior of parchment was found to be different at high water activities $\left(a_{w}>0.8\right)$. It indicates a 433 lower hygroscopic nature in the parchment which may be attributed to its lignocellulosic 434 composition. This aspect is of particular importance since Aspergillus ochraceus develops 435 principally in this region. The sorption behavior difference shown in Fig. 7 implies a moisture content 436 discontinuity at the endosperm/parchment interface, i.e., at equilibrium the moisture of parchment is 437 lower.

\subsection{Water transport coefficients}

\subsubsection{Water transport coefficient in the endosperm}

443 samples was $0.9 \mathrm{~mm}$, and the water transport coefficients obtained at different moistures are 
444 plotted in Fig. 8. The moistures associated with water transport were calculated as the mean 445 between the initial and final moisture which are considered for the slope of Eq. (13) log 446 transformation. This figure shows that the water transport coefficient depends on moisture content 447 at moistures $<0.65$. This effect confirm the fact that at high moisture contents $(>0.65)$, 448 corresponding to high activity values $\left(a_{w}>0.95\right)$, the water is practically "free", i.e., its mobility is 449 maximal, and therefore it leads a constant value for the water transport coefficient. As the moisture 450 content decreases, two phenomena participate to reduce the water diffusivity which tends to zero. 451 First, the reduction of water volume fraction inside the pore space decreases water flow; second, 452 the increase of water bonding with solid structure since hygroscopic effects become predominant. 453 Moreover, it has already been observed that, during the drying process, the entrance in the 454 hygroscopic domain corresponds to the transition from a water saturated system to a non-saturated 455 system, i.e., a gas phase appears and its volume fraction increases. Therefore, the combination of 456 these two effects account for the decreasing transport coefficient observed experimentally as the 457 moisture content tends to zero. Regarding to the silver skin, Fig. 8 results show that it leads to $10 \%$ 458 decrease of the effective diffusivity.

459 The Biot mass number were calculated with Eq. (14) using the $\Delta_{\text {wen }}$ values of Fig. 8, with 460 the following values: $l=0.009 \mathrm{~m}$ (average endosperm thickness), $k_{c}=0.007 \mathrm{~m} \cdot \mathrm{s}^{-1}$ (Geankoplis 4611998 correlation for natural convection), $\rho_{s a}=1.1 \mathrm{~kg} \cdot \mathrm{m}^{-3}, C_{s e n}=800 \mathrm{~kg} \cdot \mathrm{m}^{-3}$ and $K_{e q}=0.63$ 462 . This last value was calculated as indicate Cordova et al., (1996), and represents the average 463 distribution constant between air and product moistures at low contents in product. The mass $\mathrm{Bi}$ 464 number obtained were from 30 to 120 . These values confirm the negligible interfacial resistance 465 assumption required in Eq. (13).

\subsubsection{Averaged water transport coefficient in the whole grain with a high moisture content}

The averaged water transport coefficient at high moisture content can be evaluated from the drying kinetic of the whole bean (Fig. 9) by means of linear regression onto Eq.(15). It can be noticed in Fig. 9 that the curves show a linear behavior between $1 \mathrm{~h}$ and $4 \mathrm{~h}$ for the test at $45^{\circ} \mathrm{C}$ and between $1 \mathrm{~h}$ and $8 \mathrm{~h}$ for the test at $35^{\circ} \mathrm{C}$. It is in these intervals that are determined the

472 transport coefficients. Average initial moisture of coffee beans $\left(x_{0}\right)$ was 1.054 , and the equilibrium

473 moisture $\left(x_{e}\right)$, calculated with sorption isotherms was 0.069 . Values obtained at $35^{\circ} \mathrm{C}$ and $45^{\circ} \mathrm{C}$ 474 were respectively $(2.84 \pm 0.125) \times 10^{-11}$ and $(9.41 \pm 0.494) \times 10^{-11} \mathrm{~m}^{2} \cdot \mathrm{s}^{-1}$. The error estimation 475 represents the $95 \%$ confidence interval. The averaged transport coefficient at $45^{\circ} \mathrm{C}$ agrees with the 476 water diffusivity reported by Sfredo et al. (2005) which ranges between $1.0 \times 10^{-11}$ to $10 \times 10^{-11}$ 477 . The lower and upper limits of averaged water transport coefficient were included in the Fig.

478 8. One can note that this value agrees with the endosperm one for moisture contents higher than 
0.65. Regarding to the whole coffee bean at high moisture content, these results confirm the water

480 transport coefficients obtained for endosperm at high moisture contents. Additionally, the mass $\mathrm{Bi}$

481 number evaluated in the past section was for natural convection, and the averaged water transport

482 coefficient evaluated in this section was under forced convection. Like the interfacial mass transfer

483 is promoted by forced convection, it is evident that the use of Eq. (15), which implies a negligible

484 interfacial mass transfer, is justified.

\subsubsection{Water mass transfer resistance in parchment}

Fig. 10 shows the weight variation over time of the bottom salt solution for various experiments. After a transitional period required to equilibrate samples with both salt solutions, weight gain varies linearly allowing to identify the water resistance coefficient, $r$, by means of Eq. (16). Results are summarized in Table 1. The errors listed in Table 1 are the result of $95 \%$ confidence interval obtained from linear regression of the slope in linear zone of data in Fig. 10. The

492 water transport coefficient in parchment $\left(\Delta_{w p a}\right)$ can be determined by using Eq. (17). The 493 parchment average thickness was approximated $0.1 \mathrm{~mm}$, and the volumetric concentration of the 494 dry solid was taken $800 \mathrm{~kg} \cdot \mathrm{m}^{-3}$. The values obtained are plotted in Fig. 8. Regarding water mass 495 transfer coefficient a unique value of $5 \times 10^{-13} \mathrm{~m}^{2} \cdot \mathrm{s}^{-1}$ has been reported by Nilnont et al. (2012). 496 They estimated the water mass transfer in parchment using the water diffusivity which was 497 calculated by fitting the Fick second law solution (Eq. 13) on their drying kinetics results. Water 498 diffusivity is a common name for the water transport coefficient deduced in section 2. Moreover, the 499 reported value is two magnitude order lower than the calculated in this work. However Nilnont et al. 500 (2012) values were obtained from drying kinetics performed with $50 \mathrm{~g}$ of parchment in a tray drier 501 and they state that parchment is extremely thin but did not report this thickness. The water transport 502 coefficient obtained from Eq. (13) is highly dependent on characteristic length of diffusion. Then, the 503 values of resistance listed in Table 1, and the water transport coefficient in parchment plotted in Fig. 5048 have more confidence.

\section{CONCLUSIONS}

Coffee bean is a system extremely heterogeneous in a macroscopic level (parchment, 510 differences in their structures. Parchment structure is fibrous, very close to the wood, while that of 511 the endosperm revealed cells of form and orientation fairly uniform. This difference in structure is 512 reflected by the difference of their isotherms for water activities ranging between 0.8 and 1. This 513 difference is particularly important because it is in this interval of water activity that fungus develops.

514 It has been shown that by adopting the water chemical potential as the gradient for transport and 515 the assumption of a local equilibrium inside media, water transport can be described by a law which 
516 combine the different transport mechanisms. The averaged coefficient $\Delta_{w} X$ depends, for an

517 isothermal case and an undeformable solid phase, on the moisture content of media. Silver skin 518 weakly reduces the water transfer from the endosperm to the parchment. Furthermore, in a fresh 519 state, the silver skin is hydrated and fills the furrow. As drying goes forward, the silver skin gets 520 thinner and a gas phase appears. This could lead to fungal development in the furrow and will be 521 the focus of further investigations. The water transfer resistance of parchment associated with its 522 weak hygroscopic nature can lead to a moisture content discontinuity between external gas phase 523 and the gas phase located at the parchment/endosperm interface. This activity difference can be 524 evaluated through Eq. 17. For instance, with a mass flux corresponding to the drying kinetics at $52535^{\circ} \mathrm{C}$ (Fig. 9), the water activity difference between both sides of parchment is about 0.49 . 526 Therefore, parchment reduces the risk of Aspergillus ochraceus contamination in the endosperm if 527 compared to a case where it has been destroyed. Finally, the experimental techniques presented 528 should allow a fine analysis of the drying process inside a coffee bean, but description of water 529 transfer at the microscopic scale can only be carried out by numerical simulation. These models will 530 allow the estimation of drying conditions that prevent the fungal development.

\section{Acknowledgments}

533 The authors wish to thank Mexican CONACyT and University Montpellier 2 for the financial support

534 given for the stages and missions of A. Ramirez-Martinez in Montpellier and the missions of the 535 Professors both in Veracruz and Montpellier through the project "PCP Optimización del secado de 536 café".

AOAC., (1990). Official Methods of Analysis. Washington, DC: Association of Official Analytical Chemists.

Auria, R., Bénet, J.C., Cousin, B., \& Sainte-Beuve, J. (1991). Drying of natural rubber in sheet formInternal structure and water transfer. Journal of Natural Rubber Research, 6(4), 267-280.

Bénet, J.C., \& Jouanna, P. (1983). Non équilibre thermodynamique dans les milieux poreux non saturés avec changement de phase. International Journal of Heat and Mass Transfer, (26)11, 1585-1595.

Bénet, J.C., Lozano, A.L., Cherblanc, F., \& Cousin, B. (2009). Phase change of water in hygroscopic porous medium. Phenomenological relation and experimental analysis for water in soil. Journal of Non Equilibrium Thermodynamics, 34, 133-153. moisture content, and Density on Water diffusivity. Drying technology, 22(7), 1777-1789. 
552 Callen, H.B. (1985). Thermodynamics and an introduction to thermostatistics. 2nd edition. John 553 Wiley \& Sons

554 Córdova, A.V, Ruiz-Cabrera, M.A., \& García-Alvarado, M.A. (1996). Analytical solution for mass 555 transfer equation with interfacial resistance in Food Drying. Drying Technology, 14(7\&8), 18455561826.

557 Correa, P.C., Resende, O., \& Menezes, D. R. (2006). Drying characteristics and kinetics of coffee 558 berry. Revista Brasileira de Produtos Agroindustriais, 8, 1-10.

559 Crank, J. (1975). Mathematics of Diffusion. New York, NY: Oxford University Press.

560 De Castro, R.D., \& Marraccini, P. (2006). Cytology, biochemistry and molecular changes during 561 coffee fruit development. Brazilian Journal of Plant Physiology, 18, 175-199.

562 Eira, M.T.S., Amaral da Silva, E.A., De Castro, R.D., Dussert, S., Walters, C., Bewley, J.D., \& 563 Hilhorst, H.W.M. (2006). Coffee seed physiology. Brazilian Journal of Plant Physiology, 18, 149564163.

565 Efremov, G., \& Kudra, T. (2004). Model-based estimated for time-dependent apparent diffusivity. 566 Drying technology, 23(12), 2513-2522.

567 FAO (2008), Discussion paper on Ochratoxin A in coffee.

568 Ferro-Fontan, C., Chirife, J., Sancho, E., \& Iglesias, H.A. (1982). Analysis of a model for water 569 sorption phenomena in foods. Journal of Food Science, 47, 1590-1594.

570 Frank J.M. (2000). On the activity of fungi in coffee in relation to ochratoxin A production. In 571 Proceedings of the $10^{\text {th }}$ International Union of Pure and Applied Chemists (IUPAC) Symposium 572 on Mycotoxins and Phycotoxins, Sao Paulo, Brazil. CD-ROM.

573 Geankoplis, C.J. (1998). Transport Processes and Separation Process Principles. México, D.F.: 574 Compañía editorial continental S.A. de C.V.

575 Hernández-Díaz, W.N., Ruiz-López, I.I., Salgado-Cervantes, M.A., Rodríguez-Jimenes, G.C., \& 576 García-Alvarado, M.A. (2008). Modelling heat and mass transfer during drying of green coffee 577 beans using prolate spheroid geometry. Journal of Food Engineering, 86, 1-9.

578 Kasser, A., \& Kasser, I.M. (1969). Cellulose dissolving pulp produced from grain parchment. U.S. $579 \quad$ Patent No. 3,429,771.

580 Kouadio, A.I., Lebrihi, A., N'zi-Agbo, G., Mathieu, F., Pfohl-Leszkowiz, A., \& Bretin-Dosso, M. 581 (2007). Influence de l'interaction de la température et de l'activité de l'eau sur la croissance et la 582 production de l'ochratoxine A par Aspergillus niger, Aspergillus carbonarius et Aspergillus 583 ochraceus sur un milieu de base café. Canadian Journal of Microbiology, 53, 852-859.

584 Kuiken, G.D. (1994). Thermodynamics of irreversibles processes. New York, N.Y.: John Wiley \& 585 Sons.

586 Maroulis, Z.B., Kiranoudis, C.T., \& Marinos-Kouris, D. (1995). Heat and mass transfer modeling in 587 air drying of foods. Journal of Food Engineering, 26, 113-130.

588 Mburu, J.K. (1999). Notes on coffee processing procedures and their influence on quality. Kenya 589 Coffee, 64, 2861-2867. 
Mulet, A. (1994). Drying modeling and water diffusivity in carrots and potatoes. Journal of Food Engineering, 22, 329-348.

Müller, I. (2001) Thermodynamics of mixture and phase field theory. International Journal of Solids and Structures, 38, 1105-1113.

Mrani, I., Bénet, J.C., \& Fras, G. (1995). Transport of water in a biconstituant elastic medium. Applied Mechanics Review, 48, 717-721.

Mrani, I., \& Bénet, J.C. (2005). Relaxation des contraintes et fissuration induites par une redistribution d'eau en milieu biphasique élastique. Mécanique et Industrie, 6, 529-538.

Nilnont, W., Thepa, S., Janjai, S., Kasayapanand, N., Thamrongmas, C., \& Bala, B.K. (2012). Finite element simulation for coffee (Coffea arabica) drying. Food and Bioproducts Processing, 90, 341350.

601 Ouoba, S., Cherblanc, S., Cousin, B., \& Bénet, J.C. (2010), A new experimental method to

602 determine the sorption isotherm of a liquid in a porous medium. Environmental Science \& 603 Technology, 44(15), 5914-5919.

604 Paulino de Moraes, M.H., \& Luchese, R.H. (2003). Ochratoxin A in green coffee: influence of 605 harvest and drying processing procedures. Journal of Agricultural and Food Chemistry, 51, 58246065828.

607 Pendergrast, M. (1999). Uncommon grounds: The History of coffee and how it transformed our 608 world. New York, N.Y.: Basic Books.

609 Prigogine, I., \& Mazur, P. (1951). Sur deux formulations de l'hydrodynamique et le problème de 610 I'hélium liquide II. Physica XVII, 7, 661-693.

611 Sfredo, M.A., Finzer, J.R.D., \& Limaverde, J.R. (2005). Heat and mass transfer in coffee beans 612 drying. Journal of Food Engineering, 70, 15-25.

613 Suárez-Quiroz, M., Gonzalez-Ríos, O., Barel, M., Guyot, B., Schorr-Galindo, S., \& Guiraud, J.P. 614 (2004). Effect of chemical and enviromental factors on Aspergillus ochraceus growth and 615 toxigenesis in green coffee. Food Microbiology, 21, 629-634.

616 Sutherland, P.W., Hallett, I.C., MacRae, E., Fischer, M., \& Redgwell, R.J. (2004). Cytochemistry 617 and immunolocalisation of polysaccharides and proteoglycans in the endosperm of green Arabica 618 coffee beans. Protoplasma, 223, 203-211.

619 Taniwaki, M.H., Pitt, J.I., Teixeira, A.A., \& lamanaka, B.T. (2003). The source of ochratoxin A in 620 Brazilian coffee and its formation in relation to processing methods. International Journal of Food 621 Microbiology, 82, 173-179.

622 Wang, N., \& Brennan, J.G. (1995). A mathematical model of simultaneous heat and mass transfer 623 during drying of potato. Journal of Food Engineering, 24, 47-60. 